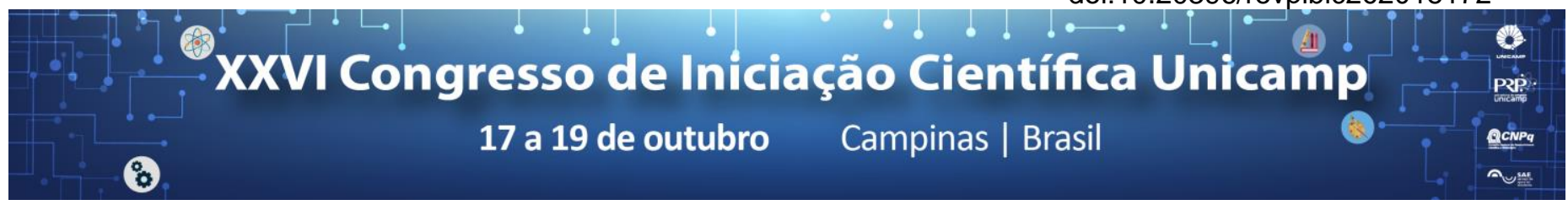

\title{
Estudo da reação de retro Diels-Alder para uso em carreadores de fármacos.
}

\author{
Arthur M. Prado*, Ronaldo A. Pilli, Ítalo O. Mazali.
}

\section{Resumo}

O objetivo desse trabalho é o estudo da reversibilidade de reações orgânicas entre a goniotalamina e outros compostos orgânicos, por meio de aquecimento, a fim de utilizar os compostos sintetizados na funcionalização de nanopartículas de sílica e magnetita, como parte de um sistema de carreamento de fármacos. Para tal fim, foram testadas as reações de Diels-Alder e adição de Michael, sendo a segunda mais efetiva. Para caracterização dos compostos sintetizados e avaliação da reversibilidade das reações, foi utilizada a técnica de ressonância magnética nuclear.

\section{Palavras-chave:}

Goniotalamina, Diels-Alder, Adição de Michael.

\section{Introdução}

A goniotalamina (GTN) é uma molécula de origem natural que apresenta importantes propriedades biológicas, como ação antimicrobiana, anti-inflamatória, além de ação antiproliferativa frente a algumas linhagens tumorais. O projeto em questão visa estudar a utilização da GTN em um sistema nanoestruturado (NP $\mathrm{Fe}_{3} \mathrm{O}_{4} @ \mathrm{SiO}_{2}$ ) de carreamento e liberação localizada de fármaco. Para isso deve ser possível ligar a molécula de GTN em outro composto orgânico que funcione como ponto de ancoragem para a nanopartícula de sílica porosa e sua reação deve ser reversível por meio de aquecimento, para proporcionar a liberação localizada do fármaco.

O objetivo do trabalho é, portanto, sintetizar os compostos orgânicos, caracterizá-los e avaliar a reversibilidade da reação frente ao aquecimento.

\section{Resultados e Discussão}

Para dar início ao projeto, testou-se a reação de DielsAlder, conhecida por ser uma reação reversível com o aquecimento. $\mathrm{O}$ dienófilo utilizado foi a molécula de GTN e como dieno, utilizou-se o furano e o ciclopentadieno, conhecidos como bons dienos, por serem eletrônicamente ricos. A figura 1 apresenta um esquema simplificado da reação.

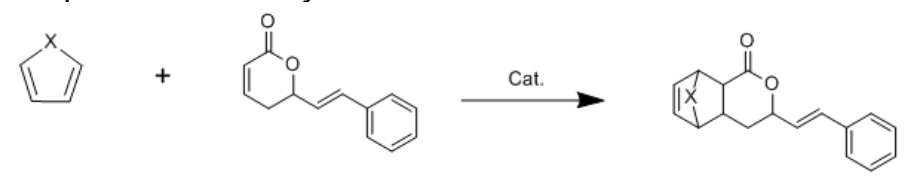

Figura 1. Esquema simplificado da reação de Diels-Alder (Furano, $\mathrm{X}=\mathrm{O}$ e Ciclopentadieno, $\mathrm{X}=\mathrm{CH}_{2}$ ).

Testou-se dois métodos, o primeiro deles utilizando $\operatorname{InCl} 3$ como catalisador e água como solvente ${ }^{1,2}$ e, no segundo, foi utilizado um complexo de $\mathrm{AlCl}_{3}$ e THF, sem solvente ${ }^{3}$, ambos em temperatura ambiente. Foi testado ainda um outro método, com um complexo de alumínio como catalisador $\left(\mathrm{Tf}_{2} \mathrm{CHAIMe}\right)^{4}$. Os adutos esperados, apesar de teoricamente plausíveis, não foram obtidos com sucesso no laboratório para nenhuma das metodologias abordadas.

Por esse motivo, optou-se por testar a reação de adição de Michael, que também se aplica a carbonilas $\alpha, \beta-$ insaturadas como a goniotalamina, sendo que há evidências de sua reversibilidade. Um esquema simplificado da reação de adição de Michael se encontra na figura 2.

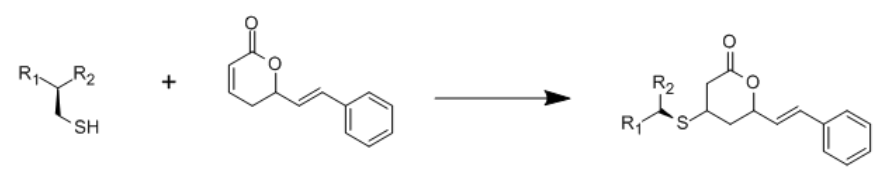

Figura 2. Esquema simplificado da reação de adição de Michael entre um tiol e a goniotalamina.

Optou-se pela utilização de derivados da cisteína para a adição à molécula de GTN, uma vez que o grupo aminoácido representa um bom ponto de ancoragem para a nanopartícula de sílica. Partiu-se então da acetilação do éster metílico da L-cisteína ${ }^{5}$, a fim de facilitar sua posterior adição à molécula de GTN. A reação se mostrou eficiente, pela análise do espectro de $\mathrm{RMN}^{1} \mathrm{H}$, com rendimento de $57 \%$. A reação entre a GTN e o éster metílico da N-acetil-L-cisteína (AcCysOMe), foi realizada em uma mistura de água e acetona à temperatura ambiente, utilizando trietilamina como catalisador6. O produto obtido foi purificado por cromatografia flash e o rendimento foi de $84 \%$.

Empregou-se a técnica de RMN para caracterização do produto e para um estudo da reversibilidade da reação, por meio da mesma técnica a temperatura variável. Foram feitos espectros para o produto na faixa de 30-60 ${ }^{\circ} \mathrm{C}$, faixa de valores ótimos para a utilização do composto na funcionalização da nanopartícula, uma vez que sua temperatura dentro do organismo não pode ser muito elevada. A análise dos espectros, no entanto, não revelou indícios de que a reação tenha se revertido.

\section{Conclusões}

A partir de todo o trabalho desenvolvido, pode-se concluir que não foi possível obter o aduto de Diels-Alder como desejado na idealização do projeto. A reação de adição de Michael, por outro lado se mostrou mais efetiva na ligação entre a AcCysOMe e a molécula de GTN, porém os estudos da reversibilidade da reação se mostraram infrutíferos e o produto da reação permaneceu estável com o aumento da temperatura.

\footnotetext{
${ }^{1}$ Fringuelli, F.; Piermatti, O.; Vaccaro, L.; Eur. J. Org. Chem., 2001, 439-455. ${ }^{2}$ Loh, T.; Pei, J.; Lin, M; Chem. Commun., 1996, 2315-2316.

${ }^{3}$ Fringuelli, F.; Girotti, R.; Pizzo, F.; Vaccaro, L.; Organic Letters, Vol. 8, No. 12, 2006

4 Yanai, H.; Takahashi, A.; Taguchi, T.; Organic Syntheses, Vol. 82, 34-42, 2005

5 Aroyan, C. E.; Miller, S. J.; J. Am. Chem. Soc., 129 (2), 256-257, 2007.

${ }^{6}$ Bickley, J. F.; Ciucci, A.; Evans, P., Roberts, S. M.; Ross, N.; Santoro, M. G.; Bioorg. Med. Chem., 12, 3221-3227, 2004.
} 